\title{
The North East Division Trainees' Day 1988
}

\author{
Christopher Bools, Karolyn Hurren and Maura Kenny, Collegiate Trainees' \\ Committee representatives, North East Division
}

The 1988 North East Division trainees' day was held in the Clinical Sciences Building at St James' University Hospital Leeds on 22 September 1988. Thirtyfive trainees attended despite the difficulties caused by the postal strike. Three guest speakers were invited: Dr Simon Baugh from Bradford, Dr Mark Aveline from Nottingham and Dr Francis Creed from Manchester. Their subjects were 'Management training', 'Training in psychotherapy as part of general professional training' and 'Trainees and research' respectively.

Dr Baugh, consultant psychiatrist, currently the assistant unit general manager for adult mental illness in Bradford, commenced by stating his enthusiasm for Griffiths-style management because of the clarification of responsibility which has led to a more active management style, never possible with consensus management, and better links between the planners at District Health Authority and clinicians. Dr Baugh pointed out that all consultants are already managers, in that they influence the prescribing of drugs and budgets for equipment and the employment of staff. Three levels of skill were outlined. It was advised that the first two levels needed to be acquired by all trainees. Level 1 is required by every consultant to ensure the development of their service and consists of basic information about organisation, planning and funding at local level. Level 2 skills include the allocation of time and budgets and are those presumed to be acquired at management courses. Level 3 skills were needed by psychiatrists interested in becoming involved at a higher level of management, e.g. a medical advisory post or a general manager. Ways of obtaining such skills include 'learning on the job', participating in a current management project, networking (informal and formal contacts with others doing a similar job) and mentoring (the setting up of a formal relationship with a management senior whom one could approach for advice). In future, senior medical staff may well be subject to Individual Performance Review. The question of how to obtain practical training was raised. In Yorkshire, one source is the Yorkshire Regional Management Training Course, organised by $\mathrm{Dr}$ Nehaul, which provides practical skills training and utilises role play exercises. Another is the action learning group which is open to senior registrars in the Yorkshire Region.
Dr Aveline asserted his belief that psychotherapy is a fundamental part of psychiatry but does not always attract the recognition that it deserves. He emphasised a central issue in training for all psychiatrists, which is that they need to hear what the patient has to say and convey that they have understood. The first depends on the ability of the listener to bear the patients' emotional pain and the second on translating empathic understanding into evident communication. Psychotherapy is an interpersonal process designed to bring about changes in those aspects of personal functioning that are the patient's responsibility; the process "should enable the patient to write a new end to sad stories". The College guidelines on psychotherapy training from 1971 and 1986 (revised) were presented in a summarised form.

The Nottingham Training Programme for premembership trainees was then described. This multidisciplinary course includes a six months preparatory period before a patient was seen for formal individual therapy. The importance of interview skills and anticipating typical therapist difficulties that may arise in dynamic psychotherapy were outlined. A questioner pointed out a personal experience of difficulties in getting started in psychotherapy training. Dr Aveline hoped that this was more a problem of the past; the situation is improving as there has been a growth in the number of psychotherapy departments outside London, with a parallel growth in senior registrar posts. This should result in a greater availability of training opportunities. The important role of the scheme organiser was stressed, especially with regard to the content of case conferences, which should illustrate the range of psychological treatments. One trainee asked who should offer training in supportive psychotherapy; a psychotherapist or a general psychiatrist? Dr Aveline favoured this important skill being taught by 'dynamically-minded' general psychiatrists.

Dr Francis Creed took up the topic of trainees and research. He suggested that the situation of ten years ago is over; no longer can one be appointed to a consultant post without having done any research. This raises a problem for trainees of today as they may be working for consultants who have no personal experience of research. Consultant expansion has slowed down and increased competition means that research experience has now become an essential 
component of the curriculum vitae. Evidence of increased interest in research is that in recent years more trainees have entered papers for the College Research Prize, although this remains a tiny number. Prior to the day, one of us (CB) had presented Dr Creed with a list of problems encountered by trainees attempting to do research, gathered from trainees at trainees' days held throughout the UK. A number of problems and possible solutions were discussed:

(a) no consultant help! - find another consultant who will help, or choose a post on your rotation scheme with the prime aim of working for a consultant who is known to supervise trainee's research

(b) there is an emphasis on large projects and publications!-not true, small projects are just as likely to get completed, possibly published and certainly to bring credit to the trainee

(c) unable to get funding! - only a minority of trainees get on to funded projects to begin with, smaller projects can demonstrate one's ability to complete and may lead to bigger projects

(d) lack of research training! - get on a course run by the college Research Committee which is particularly aimed at trainees from non-teaching centres.

Dr Creed then presented an autobiographical account of his development as a researcher as encouragement to trainees who had experience of failure in their early projects. He gave an account of small projects that could be completed within a six month placement. We were given a brief handout to illustrate how an idea can be turned into a feasible project; this exercise stimulated much enthusiasm, and encouraged trainees to get started with a project.

Trainees then divided into three groups to discuss: trainees doing research; psychotherapy training; and the implications for training arising from working in community settings. The group discussing psycho- therapy training reported a lack of availability of training opportunities across the psychotherapies, with some trainees experiencing severe difficulties and occasionally obstructive attitudes. A need was perceived for a more formal approach to training, appropriate to the level of each trainee, with the recognition that a trainee may have a flair for, e.g., behavioural psychotherapy rather than psychodynamic psychotherapy or vice versa. The group looking at trainees and research recognised an element of "distasteful self advancement" in the need to do research but also the benefits to personal intellectual satisfaction and the contribution research makes to the development of clinical services. A common difficulty was lack of supervision and it was felt that if the local tutor was not a "clinical researcher" they should direct trainees to someone able and willing to offer supervision. It was pointed out that at each College Quarterly Meeting there is an opportunity for trainees to present short papers. The group addressing the training implications of working in community settings identified a number of potential obstacles to training that need to be overcome. Concern was expressed about difficulties posed by travelling, the likely loss of mutual support and learning from being part of a peer group. Trainees felt uncertain about what the future holds in store, bearing in mind that community resources often appear to be underfunded and understaffed.

Judging by comments from trainees, the day proved informative and a feeling of shared interests developed. We thank the guest speakers for their helpful and stimulating contributions to the day. The next trainees' day of the North East Division will be held in Newcastle. As always, all trainees including those who are not inceptors will be welcome to attend.

\title{
The report of a working party of the fourth Collegiate Trainees' Committee
}

\author{
The public image of psychiatry - a pilot study
}

\author{
Dinesh BHUGRa Senior Registrar, The Maudsley Hospital, Denmark Hill, London \\ SE5 8AZ (correspondence); and JAN ScoTT Lecturer (now Senior Lecturer) in \\ Psychiatry, University of Newcastle-upon-Tyne
}

Attitudes towards psychiatry are likely to affect psychiatrists and their patients in a number of ways. The success of the move towards community based services is directly dependent upon the public's attitudes 